\title{
Klasifikasi Kinerja Asisten Laboratorium Selama Pandemi Covid-19 Menggunakan Algoritma Naïve Bayes
}

\author{
Andhika P. U. Rahmayadi ${ }^{1 *}$, Ultach Enri ${ }^{2 *}$, Purwantoro ${ }^{3 *}$ \\ * Teknik Informatika, Universitas Singaperbangsa Karawang \\ andhika.rahmayadi17052@student.unsika.ac.id ${ }^{1}$, ultach@staff.unsika.ac.id $^{2}$, purwantoro.masbro@unsika.ac.id $^{3}$
}

\begin{tabular}{l} 
Article Info \\
\hline Article history: \\
Received 2021-08-13 \\
Revised 2021-10-03 \\
Accepted 2021-10-14 \\
\hline
\end{tabular}

Keyword:

Evaluasi kinerja, Klasifikasi,

Naïve bayes,

Data mining

\begin{abstract}
Asisten laboratorium merupakan mahasiswa berprestrasi pilihan yang memiliki tugas untuk mendampingi dosen dalam proses mengajar mata kuliah praktikum. Karena wabah covid-19 di Indonesia sesuai dengan surat edaran yang dikeluarkan oleh menteri pendidikan tentang pelaksanaan belajar secara daring, hal ini menyebabkan proses praktikum beralih menjadi daring. Selama praktikum daring asisten laboratorium kesulitan untuk memonitor mahasiswa dalam proses pengajaran, maka diperlukan sebuah evaluasi apakah metode yang dibawakan oleh asisten laboratorium sudah tepat. Proses evaluasi ini dilakukan dengan menggunakan data mining dan algoritma naïve bayes. Model yang dihasilkan dapat memprediksi label puas dan tidak puas dengan evaluasi model k-fold cross validasi dan confusion matrix yang menghasilkan akurasi sebesar $87 \%$, recall sebesar $96 \%$, dan presisi sebesar $88 \%$. Berdasarkan hasil penelitian, kebijakan yang bisa diambil adalah dengan menerapkan sistem pembelajaran yang sama namun dengan peningkatan kualitas dalam pengajarannya.
\end{abstract}

\section{Pendahuluan}

\section{A. Latar Belakang}

Asisten laboratorium atau biasa dikenal aslab merupakan mahasiswa terbaik yang dipilih oleh perguruan tinggi sebagai pendamping dari kegiatan mata kuliah praktikum. Asisten laboratorium merupakan seorang yang mempunyai rasa tanggung jawab untuk menjaga dan memastikan fungsi seluruh komputer bekerja dengan baik sehingga proses belajar menjadi kondusif [1]. Peran dari asisten laboratorium sangat penting dalam proses pembelajaran, dikarenakan keterbatasan jangkauan dosen dan masalah masalah teknis seperti error atau bug dalam mengajar mahasiswa.

Dilansir dari kemendikbud.go.id Menteri Pendidikan dan Kebudayaan Nadiem Makarim menerbitkan sebuah surat edaran nomor 4 tahun 2020 tentang Pelaksanaan Dalam Masa Darurat Coronavirus Disease (Covid-19). Pada poin dua dijelaskan bahwa kegiatan belajar selama pandemi dilakukan secara daring atau jarak jauh. Maka dari itu, Universitas Singaperbangsa Karawang menerbitkan sebuah surat edaran untuk melaksanakan pembelajaran secara daring pada semester ganjil TA 2020/2021.

Praktikum seharusnya dilaksanakan di laboratorium komputer, namun dengan adanya pandemi praktikum dialihkan menjadi praktikum daring. Pelaksanaan praktikum secara daring memiliki keterbatasan baik dari asisten laboratorium maupun mahasiswa. Menurut penelitian yang telah dilakukan oleh Hutauruk [2] kendala dalam pembelajaran secara daring adalah kendala fundamental seperti koneksi internet, mahalnya biaya internet, serta dalam pelayanan yang diberikan selama pembelajaran. Karena dilaksanakannya praktikum secara daring, asisten laboratorium kesulitan dalam memonitoring mahasiswa selama praktikum berlangsung. Maka diperlukan sebuah evaluasi kinerja asisten laboratorium ketika mengajar secara daring. Salah satu cara untuk mengevaluasi kinerja ini dengan memakai teknik dari data mining.

Data mining adalah sebuah cara mengekstrasi dan identifikasi informasi yang bermanfaat dari sebuah basis data dengan menggunakan teknik statistik, matematik, dan kecerdasan buatan [3]. Data mining merupakan proses 
penambangan pola dan pengetahuan dari sekumpulan data, dan memecahkan masalah dengan menganalisis dari data yang sudah ada.

Naïve bayes adalah satu algoritma data mining untuk melakukan klasifikasi. Klasifikasi menggunakan algoritma ini lebih disukai karena kecepatan dan juga kesederhanaannya, meskipun sederhana tetapi hasil yang didapat selalu mencapai performa yang setara dengan algoritma lain [4]

Penelitian yang dilakukan oleh Nunu Nurdiana, Abijar Algifari [5] menyatakan bahwa hasil yang diperoleh dengan menggunakan algoritma naïve bayes mendapatkan nilai akurasi lebih tinggi $2 \%$ dibanding algoritma ID3. Naïve bayes mendapatkan nilai akurasi 76\% dan ID3 74\%. Sedangkan untuk nilai AUC dari kedua model tidak jauh beda dan termasuk kedalam kategori Fair Classification.

Penelitian yang serupa yang dilakukan oleh Supriyatna [3] menjelaskan bahwa performa algoritma naive bayes mampu memprediksi semua kelas secara tepat dengan nilai akurasi mencapai 100\%, sedangkan SVM mampu memprediksi semua kelas dengan tepat dengan nilai akurasi $80 \%$. Dengan demikian algoritma naüve bayes lebih unggul daripada algoritma SVM dan ID3.

Penelitian yang dilakukan oleh Bob gary et. al [6] menyatakan bahwa teknik data mining dapat diterapkan untuk mengevaluasi kinerja guru. Algoritma yang digunakan dalam penelitian ini adalah c4.5 yang menghasilkan akurasi sebesar $82 \%$ dan dikategorikan sebagai excellent classification.

Berdasarkan penelitian sebelumnya, maka penelitian ini akan menggunakan algoritma naïve bayes untuk klasifikasi kinerja aslab dengan menggunakan rapidminer studio sebagai alat bantu dan k-fold cross validasi dan confusion matrix sebagai teknik evaluasi model.

\section{B. Kajian Pustaka}

Untuk mendukung penelitian ini, diperlukan beberapa studi literatur sebagai bahan referensi penelitian ini.

\section{1) Algoritma Nä̈ve Bayes}

Algoritma naïve bayes adalah suatu algoritma dalam teknik klasifikasi yang cukup popular. Nä̈ve bayes masuk kedalam pembelajaran supervised, yang artinya pada tahap awal pelatihan, model diberikan sebuah data awal untuk pengambilan keputusan model tersebut. Pada proses klasifikasi, setiap data dihitung nilai probabilitas pada tiap kelas. Nä̈ve bayes sendiri adalah sebuah perhitungan dalam teorema bayes, teorema bayes sendiri memiliki persamaan sebagai berikut:

$$
P(A \mid B)=\frac{P(B \mid A) P(A)}{P(B)}
$$

Dimana:

$\mathrm{B}=$ data dari kelas yang tidak diketahu

$\mathrm{A}=$ hipotesis dari data yang berupa suatu kelas spesifik

$\mathrm{P}(\mathrm{A} \mid \mathrm{B})=$ peluang dari hipotesis $\mathrm{A}$ berdasarkan kondisi $\mathrm{B}$
$\mathrm{P}(\mathrm{A})=$ peluang dari hipotesis $\mathrm{A}$

$\mathrm{P}(\mathrm{B} \mid \mathrm{A})=$ peluang dari $\mathrm{B}$ terhadap kondisi hipotesis $\mathrm{A}$

$\mathrm{P}(\mathrm{B})=$ peluang dari $\mathrm{B}$

\section{2) Cross validation}

Cross validation merupakan sebuah teknik statistika yang biasa di pakai dalam evaluasi kinerja dari sebuah model atau algoritma yang dimana data tersebut akan dipisah kedalam dua bagian yaitu data pembelajaran dan data validasi. Pemilihan jenis dari cross validation dapat berdasarkan ukuran dataset, pada umumnya menggunakan $k$ fold cross validation dipakai karena $k$ fold cross validation sendiri dapat mengurangi beban proses komputasi dan tetap menjaga keakuratan estimasi [7].

\section{3) Confusion matrix}

Confusion Matrix ialah sebuah teknik yang mempunyai fungsi menganalisisa hasil klasifikasi sebuah tuple yang memiliki kelas berbeda dan dapat digunakan juga dalam menemukan nilai akurasi [8]. Akurasi sendiri merupakan sebuah rasio dari prediksi yang benar dengan keseluruhan data.

\section{METODOLOGI PENELITIAN}

Metodologi penelitian yang akan digunakan dalam penelitian ini adalah Knowledge Discovery in Databases (KDD). Knowledge Discovery in Databases (KDD) merupakan sebuah proses menemukan informasi yang berguna dalam database [9]. Alasan penggunaan metodologi ini adalah karena pada metodologi ini memiliki sifat yang interaktif dan iterative, melibatkan pengguna dalam membuat keputusan dan dapat dilakukan pengulangan antara dua langkah [10]. Adapun tahapan dalam Knowledge Discovery in Databases (KDD) sebagai berikut:

1) Seleksi Data (Data Selection).

2) Pemilihan Data (Preprocessing).

3) Transformasi Data (Data Transformation).

4) Data Mining.

5) Evaluasi/Interpretasi.

\section{Hasil dan Pembahasan}

Hasil dari penelitian ini menggunakan dataset yang didapatkan melalui media kuesioner yang dibagikan secara daring dengan kriteria responden mahasiswa aktif fakultas ilmu komputer universitas singaperbangsa karawang tahun angkatan 2018-2020. Kuesioner terlebih dahulu diuji validitas dan reabilitasnya, setelah dinyatakan valid maka kuesioner disebar kembali guna mendapatkan data yang akan digunakan dalam penelitian ini. Data yang didapat akan diolah sesuai dengan tahapan Knowledge Discovery in Database (KDD).

\section{1) Data selection}

Pengumpulan dilakukan selama 15 hari dengan data yang terkumpul sebanyak 260 data. Dataset didapatkan melalui penyebaran kuesioner secara daring melalui media 
google form dengan kriteria mahasiswa fakultas ilmu komputer universitas singaperbangsa karawang tahun angkatan 2018 - 2020. Dari 260 data yang sudah didapat dilakukan seleksi atribut yang akan digunakan untuk proses pembuatan model.

Setelah data diseleksi, data yang dipakai sebanyak 254 . Hal ini berdasarkan dari perhitungan minimum sampel terhadap populasi yang diteliti menggunakan rumus slovin yaitu sebanyak 254 minimal sampel dari 693 populasi mahasiswa fakultas ilmu komputer universitas singaperbangsa karawang dari angkatan 2018-2020. Sampel diambil dengan teknik random sampling.

\section{2) Preprocessing}

Setelah melakukan seleksi atribut pada dataset, dilanjutkan dengan preprocessing data. Preprocessing data yang dilakukan yaitu penghapusan data ganda pada dataset serta menghilangkan beberapa atribut yang tidak dipakai untuk proses pembuatan model. Atribut yang digunakan yaitu atribut P1 - P12 dan atribut label sebagai label dari dataset. Atribut yang dihapus untuk proses modeling yaitu atribut program studi, dan semester. Dataset yang digunakan awalnya berjumlah 260 data, setelah dicek dengan menggunakan fungsi duplicate data menggunakan Microsoft excel terdapat data ganda sebanyak 4 data. data yang digunakan sebanyak 254 data.

\section{3) Data Transformation}

Pada tahap ini data dilakukan proses transformasi, namun karena data yang didapatkan sudah sesuai dan bisa diproses oleh algoritma naïve bayes maka proses transformasi tidak dilakukan.

\section{4) Data mining}

Pada tahap ini, data yang sudah ditransformasi pada tahap sebelumnya akan dilakukan pengolahan dengan menggunakan algoritma naïve bayes. Tabel 1 merupakan data yang akan digunakan untuk pemodelan dengan menggunakan algoritma naive bayes.

TABEL I

DATA LATIH

\begin{tabular}{|c|c|c|c|c|c|c|}
\hline No & P1 & P2 & P3 & P4 & P5 & P6 \\
\hline 1 & S & Ya & SS & SS & Ya & SS \\
\hline 2 & N & Tidak & S & S & Ya & SS \\
\hline 3 & S & Ya & S & S & Ya & S \\
\hline.. &.. &.. &.. &.. &.. &.. \\
\hline.. &.. &.. &.. &.. &.. &.. \\
\hline 252 & S & Ya & S & S & Ya & S \\
\hline 253 & S & Ya & S & S & Ya & S \\
\hline 254 & S & Ya & S & S & Ya & S \\
\hline
\end{tabular}

TABEL II

DATA LATIH LANJUTAN

\begin{tabular}{|c|c|c|c|c|c|c|}
\hline P7 & P8 & P9 & P10 & P11 & P12 & Label \\
\hline S & SS & Tidak & Ya & SS & SS & Puas \\
\hline SS & N & Tidak & Tidak & N & S & Puas \\
\hline S & SS & Ya & Ya & S & S & Puas \\
\hline.. &.. &.. &.. &.. &.. &.. \\
\hline.. &.. &.. &.. &.. &.. &.. \\
\hline SS & SS & Ya & Ya & S & SS & Puas \\
\hline S & SS & Ya & Ya & S & SS & Puas \\
\hline S & SS & Ya & Ya & S & S & Puas \\
\hline
\end{tabular}

Keterangan:

STS $=$ sangat tidak setuju

TS $=$ tidak setuju

$\mathrm{N}=$ netral

$\mathrm{S}=$ setuju

$\mathrm{SS}=$ sangat setuju

TABEL III

ATRIBUT DATASET

\begin{tabular}{|c|l|}
\hline Atribut & \multicolumn{1}{|c|}{ Pertanyaan } \\
\hline P1 & $\begin{array}{l}\text { Menurut anda, apakah pembahasan materi praktikum } \\
\text { secara daring yang diberikan aslab dapat dipahami dengan } \\
\text { baik? }\end{array}$ \\
\hline P2 & $\begin{array}{l}\text { Menurut anda, apakah aslab sudah mengawas dan } \\
\text { mengajar praktikum daring sesuai jadwal praktikum dan } \\
\text { tepat waktu? }\end{array}$ \\
\hline P3 & $\begin{array}{l}\text { Menurut anda, apakah aslab memberikan contoh yang } \\
\text { relevan dengan materi praktikum? }\end{array}$ \\
\hline P4 & $\begin{array}{l}\text { Menurut anda, apakah aslab saat praktikum daring secara } \\
\text { live coding dapat menyampaikan materi praktikum dengan } \\
\text { baik dan jelas? }\end{array}$ \\
\hline P5 & $\begin{array}{l}\text { Apakah selama praktikum daring anda dapat mengikuti } \\
\text { materi yang diberikan? }\end{array}$ \\
\hline P6 & $\begin{array}{l}\text { Apakah setelah praktikum daring anda dapat menguasai } \\
\text { materi praktikum yang di berikan oleh aslab? }\end{array}$ \\
\hline P7 & $\begin{array}{l}\text { Menurut anda, apakah aslab responsif dalam menjawab } \\
\text { permasalahan yang anda hadapi? }\end{array}$ \\
\hline P8 & $\begin{array}{l}\text { Apakah aslab memberikan akses link pengumpulan tugas } \\
\text { secara kolektif menggunakan media penyimpanan gdrive } \\
\text { sehingga dapat mempermudah mahasiswa? }\end{array}$ \\
\hline P9 & Apakah aslab memberikan penilaian secara objektif? \\
\hline P10 & Apakah aslab memberikan transparasi nilai praktikum? \\
\hline P11 & $\begin{array}{l}\text { Menurut anda, apakah aslab sudah memberikan solusi } \\
\text { dalam melaksanakan praktikum daring menggunakan } \\
\text { media yang dipilih? }\end{array}$ \\
\hline P12 & $\begin{array}{l}\text { Menurut anda dengan menggunakan media yang dipilih } \\
\text { sangat praktis dalam mengajar dan membahas materi } \\
\text { praktikum? }\end{array}$ \\
\hline
\end{tabular}

Dari data latih pada tabel I, hal yang pertama dilakukan yaitu mencari probabilitas kelas B1 "puas" dan B0 "tidak puas" terlebih dahulu. Dari data tersebut didapatkan kelas "puas" berjumlah 220, dan kelas "tidak puas" berjumlah 34. Perhitungan probabilitas untuk kelas puas dapat dilakukan dengan menggunakan persaman berikut. 


$$
\mathrm{P}(\mathrm{B} 1)=220 / 254=0,866
$$

Sedangkan perhitungan probabilitas untuk kelas tidak puas dapat dilakukan dengan menggunakan persamaan berikut.

$$
\mathrm{P}(\mathrm{B} 0)=34 / 254=0,133
$$

Setelah didapatkan masing masing probabilitas dari kelas "puas" dan "tidak puas", selanjutnya dilakukan perhitungan terhadap masing masing atribut yang digunakan dalam proses pemodelan. Perhitungan setiap probabilitas akan dijelaskan sebagai berikut.

Berdasarkan data uji sebanyak 254 data didapatkan kelas puas untuk atribut P1 yang bernilai Sangat Tidak Setuju terdapat sebanyak 0, P1 yang bernilai Tidak Setuju sebanyak 5, P1 yang bernilai Netral sebanyak 46, P1 yang bernilai Setuju sebanyak 115, dan P1 yang bernilai Sangat Setuju sebanyak 54. Sedangkan kelas tidak puas untuk P1 yang bernilai 1 terdapat sebanyak $1, \mathrm{P} 1$ yang bernilai 2 sebanyak 8, P1 yang bernilai 3 sebanyak 14, P1 yang bernilai 4 sebanyak 9, dan P1 yang bernilai 5 sebanyak 2 . Probabilitas dari atribut P1 dapat dilihat pada tabel IV sebagai berikut.

TABEL IV

PROBABILITAS P1

\begin{tabular}{|c|c|c|}
\hline $\mathrm{P} \mid \mathrm{P} 1 \ldots$ & Puas & Tidak Puas \\
\hline Sangat Tidak Setuju & 0 & 0,03 \\
\hline Tidak Setuju & 0,02 & 0,24 \\
\hline Netral & 0,21 & 0,41 \\
\hline Setuju & 0,52 & 0,26 \\
\hline Sangat Setuju & 0,25 & 0,06 \\
\hline & $100 \%$ & $100 \%$ \\
\hline
\end{tabular}

Untuk perhitungan probabilitas P2 sampai P12 dapat dilihat pada tabel V sebagai berikut.

TABEL V

PROBABILITAS P2-P12

\begin{tabular}{|c|c|c|c|}
\hline & Sangat Setuju & 0,27 & 0,03 \\
\hline & & $100 \%$ & $100 \%$ \\
\hline \multirow{3}{*}{$\mathrm{P} \mid \mathrm{P} 5 \ldots$} & Tidak & 0,05 & 0,53 \\
\hline & Ya & 0,95 & 0,47 \\
\hline & & $100 \%$ & $100 \%$ \\
\hline \multirow{6}{*}{$\mathrm{P} \mid \mathrm{P} 6 \ldots$} & Sangat Tidak Setuju & 0 & 0,059 \\
\hline & Tidak Setuju & 0,05 & 0,176 \\
\hline & Netral & 0,27 & 0,618 \\
\hline & Setuju & 0,46 & 0,147 \\
\hline & Sangat Setuju & 0,22 & 0 \\
\hline & & $100 \%$ & $100 \%$ \\
\hline \multirow{6}{*}{$\mathrm{P} \mid \mathrm{P} 7 \ldots$} & Sangat Tidak Setuju & 0 & 0,03 \\
\hline & Tidak Setuju & 0,01 & 0,12 \\
\hline & Netral & 0,20 & 0,24 \\
\hline & Setuju & 0,41 & 0,50 \\
\hline & Sangat Setuju & 0,37 & 0,12 \\
\hline & & $100 \%$ & $100 \%$ \\
\hline \multirow{6}{*}{$\mathrm{P} \mid \mathrm{P} 8 \ldots$} & Sangat Tidak Setuju & 0,08 & 0,24 \\
\hline & Tidak Setuju & 0,03 & 0,03 \\
\hline & Netral & 0,15 & 0,18 \\
\hline & Setuju & 0,30 & 0,32 \\
\hline & Sangat Setuju & 0,45 & 0,24 \\
\hline & & $100 \%$ & $100 \%$ \\
\hline \multirow{3}{*}{$\mathrm{P} \mid \mathrm{P} 9 \ldots$} & Tidak & 0,04 & 0,18 \\
\hline & $\mathrm{Ya}$ & 0,96 & 0,82 \\
\hline & & $100 \%$ & $100 \%$ \\
\hline \multirow{3}{*}{$\mathrm{P} \mid \mathrm{P} 10 \ldots$} & Tidak & 0,25 & 0,59 \\
\hline & Ya & 0,75 & 0,41 \\
\hline & & $100 \%$ & $100 \%$ \\
\hline \multirow{6}{*}{$\mathrm{P} \mid \mathrm{P} 11 \ldots$} & Sangat Tidak Setuju & 0 & 0,03 \\
\hline & Tidak Setuju & 0,01 & 0,09 \\
\hline & Netral & 0,16 & 0,35 \\
\hline & Setuju & 0,53 & 0,47 \\
\hline & Sangat Setuju & 0,30 & 0,06 \\
\hline & & $100 \%$ & $100 \%$ \\
\hline \multirow{6}{*}{$\mathrm{P} \mid \mathrm{P} 12 \ldots$} & Sangat Tidak Setuju & 0,00 & 0,12 \\
\hline & Tidak Setuju & 0,01 & 0,24 \\
\hline & Netral & 0,18 & 0,26 \\
\hline & Setuju & 0,46 & 0,38 \\
\hline & Sangat Setuju & 0,34 & 0 \\
\hline & & $100 \%$ & $100 \%$ \\
\hline
\end{tabular}

\begin{tabular}{|c|c|c|c|}
\hline \multicolumn{2}{|c|}{} & Puas & Tidak Puas \\
\hline \multirow{4}{*}{$\mathrm{P} \mid \mathrm{P} 2 \ldots$} & Tidak & 0,06 & 0,38 \\
\cline { 2 - 4 } & Ya & 0,94 & 0,62 \\
\cline { 2 - 4 } & & $100 \%$ & $100 \%$ \\
\hline \multirow{4}{*}{$\mathrm{P} \mid \mathrm{P} 3 \ldots$} & Sangat Tidak Setuju & 0 & 0,09 \\
\cline { 2 - 4 } & Tidak Setuju & 0,04 & 0,24 \\
\cline { 2 - 4 } & Netral & 0,17 & 0,15 \\
\cline { 2 - 4 } & Setuju & 0,53 & 0,44 \\
\cline { 2 - 4 } & Sangat Setuju & 0,26 & 0,09 \\
\cline { 2 - 4 } & & $100 \%$ & $100 \%$ \\
\hline \multirow{4}{*}{ P $\mid$ P4 ... } & Sangat Tidak Setuju & 0 & 0,12 \\
\cline { 2 - 4 } & Tidak Setuju & 0,04 & 0,29 \\
\cline { 2 - 4 } & Netral & 0,22 & 0,35 \\
\cline { 2 - 4 } & Setuju & 0,47 & 0,21 \\
\hline
\end{tabular}

Setelah perhitungan dari probabilitas setiap atribut, dapat dilakukan sebuah tes uji model yang dibuat dengan 
menggunakan data baru. Data uji dapat dilihat pada tabel VI sebagai berikut.

TABEL VI

DATA UJI

\begin{tabular}{|c|c|c|c|c|c|c|c|c|c|c|c|c|c|}
\hline No & P1 & P2 & P3 & P4 & P5 & P6 & P7 & P8 & P9 & P10 & P11 & P12 & L \\
\hline 1 & SS & Ya & S & S & Ya & S & S & S & Ya & Ya & S & S & ? \\
\hline
\end{tabular}

Dari data uji pada tabel VI, kita dapat melakukan perhitungan prediksi dari perhitungan probabilitas yang sudah dibuat. Dengan kriteria $A=\{\mathrm{P} 1=$ Sangat Setuju, P2 = Tidak, P3 = Setuju, P5 = Ya, P6 = Setuju, P7 = Setuju, $\mathrm{P} 8=$ Setuju, P9 $=$ Ya, P10 = Ya, P11 = Setuju, P12 = Setuju\} kemudian dihitung nilai setiap masing masing atribut untuk prediksi "tidak puas", dengan hitungan sebagai berikut.

- $\quad \mathrm{P}(\mathrm{A} \mid \mathrm{B} 0)=\mathrm{P}(\mathrm{P} 1=\mathrm{SS} \mid \mathrm{B} 0) \times \mathrm{P}(\mathrm{P} 2=\mathrm{Ya} \mid \mathrm{B} 0) \mathrm{x}$ $\mathrm{P}(\mathrm{P} 3=\mathrm{S} \mid \mathrm{B} 0) \times \mathrm{P}(\mathrm{P} 5=\mathrm{Ya} \mid \mathrm{B} 0) \times \mathrm{P}(\mathrm{P} 6=\mathrm{S} \mid$ $\mathrm{B} 0) \times \mathrm{P}(\mathrm{P} 7=\mathrm{S} \mid \mathrm{B} 0) \times \mathrm{P}(\mathrm{P} 8=\mathrm{S} \mid \mathrm{B} 0) \times \mathrm{P}(\mathrm{P} 9=$ $\mathrm{Ya} \mid \mathrm{B} 0) \times \mathrm{P}(\mathrm{P} 10=\mathrm{Ya} \mid \mathrm{B} 0) \times \mathrm{P}(\mathrm{P} 11=\mathrm{S} \mid \mathrm{B} 0) \times$ $\mathrm{P}(\mathrm{P} 12=\mathrm{S} \mid \mathrm{B} 0)$

- $\quad \mathrm{P}(\mathrm{A} \mid \mathrm{B} 0)=0,06 \times 0,62 \times 0,44 \times 0,21 \times 0,47 \times$ $0,147 \times 0,50 \times 0,32 \times 0,82 \times 0,41 \times 0,47 \times 0,38=$ 0,0000023

Setelah didapatkan nilai $\mathrm{P}(\mathrm{A} \mid \mathrm{B} 0)$, maka selanjutnya dapat dilakukan perhitungan untuk prediksi "puas" dengan cara yang sama yaitu mengkalikan semua nilai probabilitas setiap atribut pada kelas "puas", dengan hitungan sebagai berikut.

- $\mathrm{P}(\mathrm{A} \mid \mathrm{B} 1)=\mathrm{P}(\mathrm{P} 1=\mathrm{SS} \mid \mathrm{B} 1) \times \mathrm{P}(\mathrm{P} 2=\mathrm{Ya} \mid \mathrm{B} 1) \mathrm{x}$ $\mathrm{P}(\mathrm{P} 3=\mathrm{S} \mid \mathrm{B} 1) \times \mathrm{P}(\mathrm{P} 5=\mathrm{Ya} \mid \mathrm{B} 1) \times \mathrm{P}(\mathrm{P} 6=\mathrm{S} \mid$ $\mathrm{B} 1) \times \mathrm{P}(\mathrm{P} 7=\mathrm{S} \mid \mathrm{B} 1) \times \mathrm{P}(\mathrm{P} 8=\mathrm{S} \mid \mathrm{B} 1) \times \mathrm{P}(\mathrm{P} 9=$ $\mathrm{Ya} \mid \mathrm{B} 1) \times \mathrm{P}(\mathrm{P} 10=\mathrm{Ya} \mid \mathrm{B} 1) \times \mathrm{P}(\mathrm{P} 11=\mathrm{S} \mid \mathrm{B} 1) \mathrm{x}$ $\mathrm{P}(\mathrm{P} 12=\mathrm{S} \mid \mathrm{B} 1)=\mathrm{P}(\mathrm{A} \mid \mathrm{B} 1)=0,00053$

Setelah semua nilai didapatkan, dilanjutkan dengan perhitungan maksimal untuk setiap prediksi kelas dengan cara mengkalikan nilai tersebut dengan nilai probabilitas dari setiap kelasnya. Perhitungannya sebagai berikut.

- $\quad \mathrm{P}(\mathrm{B} 0 \mid \mathrm{A})=\mathrm{P}(\mathrm{A} \mid \mathrm{B} 0) \times \mathrm{P}(\mathrm{B} 0)=0,0000023 \times$ $0,134=0,0000003082$

- $\quad \mathrm{P}(\mathrm{B} 1 \mid \mathrm{A})=\mathrm{P}(\mathrm{A} \mid \mathrm{B} 1) \times \mathrm{P}(\mathrm{B} 1)=0,00053 \times 0,866$ $=0,0004589$

Berdasarkan hitungan yang sudah dilakukan diatas didapatkan nilai $\mathrm{P}(\mathrm{B} 0 \mid \mathrm{A})=0,0000003082$ dan $\mathrm{P}(\mathrm{B} 1 \mid \mathrm{A})$ $=0,0004589$, nilai ini kemudian dibandingkan satu sama lain. Berdasarkan nilai tersebut dapat diambil kesimpulan bahwa P (B1 $\mid \mathrm{A})>\mathrm{P}(\mathrm{B} 0 \mid \mathrm{A})$ maka data uji pada tabel 4.23 tersebut diprediksi termasuk kedalam kelas "puas" dengan kinerja aslab.

5) Evaluation
Setelah proses pemodelan pada tahap sebelumnya, model diuji dengan menggunakan cross validasi dengan nilai $\mathrm{k}=10$, yang mana data akan dibagi kedalam 10 dengan sama rata dan pada setiap bagian akan ada satu data dimana data tersebut menjadi data uji dari setiap iterasinya. Tabel VII berikut merupakan hasil dari evaluasi model dengan menggunakan cross validasi.

TABEL VII

Hasil Evaluasi MengGunaKan Cross Validas

\begin{tabular}{|c|c|c|}
\hline & true Puas & true Tidak Puas \\
\hline pred. Puas & 195 & 8 \\
\hline pred. Tidak Puas & 25 & 26 \\
\hline
\end{tabular}

Berdasarkan dari hasil evaluasi diatas dapat dilihat bahwa dapat dilakukan perhitungan untuk mendapatkan nilai akurasi, recall, dan presisi dari model yang sudah dibuat. Berikut perhitungan dari akurasi, recall, dan presisi sebagai berikut.

- $\quad$ Akurasi $=195+26 / 195+26+25+8=0,87$

- $\quad$ Recall $=195 / 195+8=0,96$

- Presisi $=195 / 195+25=0,88$

Dari perhitungan yang sudah dilakukan, dapat disimpulkan bahwa akurasi dari model yang diuji menggunakan cross validasi mendapatkan hasil sebesar $87 \%$, nilai recall dari model mendapatkan hasil sebesar $96 \%$, dan nilai presisi sebesar $88 \%$. Berdasarkan hasil perhitungan diatas model yang dihasilkan sudah bagus karena mendapatkan akurasi diatas $80 \%$.

Berdasarkan data yang didapatkan sebanyak $87 \%$ mahasiswa fakultas ilmu komputer universitas singaperbangsa karawang puas dengan kinerja aslab dalam melaksanakan praktikum secara daring dan $13 \%$ tidak puas dengan sebaran data dari mahasiswa semester 6 dengan 90 data didapatkan $87 \%$ puas dan $13 \%$ lainnya tidak puas, untuk mahasiswa semester 4 dengan 96 data didapatkan $85 \%$ puas dan $15 \%$ lainnya tidak puas, dan untuk mahasiswa semester 2 dengan 70 data didapatkan $88 \%$ puas dan $12 \%$ lainnya tidak puas. Hal ini menyatakan mahasiswa semeseter 4 yang memiliki persentase tidak puas dengan kinerja aslab paling tinggi.

\section{KESIMPULAN}

Bedasarkan hasil penelitian yang sudah dilakukan dapat ditarik beberapa kesimpulan dari penelitian, evaluasi kinerja aslab dapat dilakuan melalui teknik data mining dengan menggunakan algoritma naïve bayes.

Penerapan algoritma naïve bayes untuk klasifikasi kinerja asisten lab bisa diterapkan. Data bersumber dari data penilaian mahasiswa terhadap kinerja asisten lab dengan jumlah data sebanyak 254. Bedasarkan perhitungan algoritma naïve bayes, diperoleh klasifikasi dengan label puas sebanyak 220 dan label tidak puas sebanyak 34 . 
Algoritma nä̈ve bayes bisa menampilkan dua label dari hasil klasifikasi dengan nilai akurasi sebesar $87 \%$, recall sebesar $96 \%$, dan presisi sebesar $88 \%$ dengan pengujian menggunakan cross validasi dan tools rapidminer studio.

\section{DAFTAR PUSTAKA}

[1] V. H. Pranatawijaya, W. Widiatry, R. Priskila, and P. B. A. A. Putra, "Penerapan Skala Likert dan Skala Dikotomi Pada Kuesioner Online," J. Sains dan Inform., vol. 5, no. 2, pp. 128-137, 2019, doi: 10.34128/jsi.v5i2.185.

[2] A. Hutauruk and R. Sidabutar, "Kendala pembelajaran daring selama masa pandemi di kalangan mahasiswa pendidikan matematika: Kajian kualiatatif deskriptif," J. Math. Educ. Appl., vol. 02, no. 01, pp. 45-51, 2020.

[3] A. Supriyatna and W. P. Mustika, "Komparasi Algoritma Naive bayes dan SVM Untuk Memprediksi Keberhasilan Imunoterapi Pada Penyakit Kutil," J-SAKTI (Jurnal Sains Komput. dan Inform., vol. 2, no. 2, p. 152, 2018, doi: 10.30645/j-sakti.v2i2.78.

[4] Sulistyowati, H. S., Bharata, H. K., \& ST, M. (2020). Optimasi Skripsi Mahasiswa Teknik Informatika Menggunakan Klasifikasi Algoritma Naive Bayes Dan Support Vector Machine. Journal Informatics, Science \& Technology, 10(1).

[5] N. Nurdiana and A. Algifari, "Naive Bayes Untuk Klasifikasi Penyakit," pp. 18-23, 2015.

[6] B. G. Gerardo, S. Saifullah, and E. Irawan, "Teknik Data Mining Dalam Penilaian Pengajaran Guru Berdasarkan Indeks Kepuasan Siswa," KOMIK (Konferensi Nas. Teknol. Inf. dan Komputer), vol. 3, no. 1, pp. 508-514, 2019, doi: 10.30865/komik.v3i1.1634.

[7] A. Y. Permana and M. M. Effendi, "Optimasi Stemming Porter KBBI dan Cross Validation Naïve Bayes untuk Klasifikasi Topik Soal UN Bahasa Indonesia," J. Ilm. Komputasi, vol. 17, no. 4, 2018, doi: 10.32409/jikstik.17.4.2492.

[8] F. Romadoni, Y. Umaidah, and B. N. Sari, "Text Mining Untuk Analisis Sentimen Pelanggan Terhadap Layanan Uang Elektronik Menggunakan Algoritma Support Vector Machine," J. Sisfokom (Sistem Inf. dan Komputer), vol. 9, no. 2, p. 247, 2020, doi: 10.32736/sisfokom.v9i2.903.

[9] H. Juliansa, "Data Mining Rough Set Dalam Menganalisa Kinerja Dosen Stmik Bina Nusantara Jaya Lubuklinggau," JUSIM (Jurnal Sist. Inf. Musirawas), vol. 4, no. 1, pp. 11-17, 2019, doi: 10.32767/jusim.v4i1.440.

[10] J. N. Apriliana, Natalis Ransi, "Implementasi Text Mining Klasifikasi Skripsi Menggunakan Metode Naïve Bayes Classifier," Semant.Vol.3, No.2, Jul-Des 2017, vol. 3, no. 2, pp. 187-194, 2017, doi: 10.1007/978-1-4471-7307-6_20. 